\title{
FALAR DE SI, FALAR DO OUTRO: O PERSONAGEM ARTURO BANDINI, DE JOHN FANTE
}

\author{
Lucimara de Andrade ${ }^{1^{*}}$ \\ ${ }^{1}$ Pesquisadora independente, Belo Horizonte, MG, Brasil \\ Matheus Roedel Evangelista ${ }^{2 * *}$ \\ ${ }^{2}$ Professor na Rede Pública Estadual de Minas Gerais, Belo Horizonte, MG, Brasil
}

\begin{abstract}
Resumo
Os romances analisados têm como elo o personagem Arturo Bandini, considerado alter ego do escritor John Fante, cujo contexto é o da Grande Depressão americana: Wait Until Spring, Bandini (1938), The Road to Los Angeles (cronologicamente este é o primeiro romance da saga, mas foi publicado apenas postumamente, em 1985), Ask the Dust (1939) e Dreams from Bunker Hill (1982). Considerando as temáticas e o estilo de escrita de John Fante nos romances aqui discutidos, podemos relacioná-los à experiência do escritor marginal em um panorama nada favorável: um futuro pouco promissor em um país que amarga um cenário econômico recessivo. Forjado para a escrita, Bandini configura-se como uma espécie de espelhamento do autor, um personagem no qual Fante se insere através do tempo e da narrativa no âmbito da escrita de cunho autobiográfico.

Palavras-chave: alter ego; Arturo Bandini; John Fante; escrita de si; literatura em língua inglesa
\end{abstract}

\section{TALKING ABOUT ONESELF, TALKING ABOUT THE OTHER: JOHN FANTE'S CHARACTER ARTURO BANDINI}

\begin{abstract}
The analyzed novels are linked to the character Arturo Bandini, considered an alter ego of the writer John Fante whose context is that of the Great Depression: Wait Until Spring, Bandini (1938), The Road to Los Angeles (chronologically this is the first novel in the saga, but it was published only posthumously in 1985), Ask the Dust (1939) and Dreams from Bunker
\end{abstract}

\footnotetext{
* Licenciada em Letras (2008), Mestre em Teoria literária e Crítica da Cultura (2011) pela Universidade Federal de São João del-Rei (UFSJ) e Doutora em Teoria da Literatura e Literatura Comparada (2017) pela Universidade Federal de Minas Gerais (UFMG). Atualmente é Assessora científica da Fundação de Amparo à Pesquisa do Estado de São Paulo (FAPESP). E-mail: ludeanbr@yahoo.com.br. Orcid ID: http://orcid.org/0000-0002-52611036.

** Licenciado em Letras e Mestre em Literatura Brasileira pela Universidade Federal de Minas Gerais (UFMG). Atualmente é professor da Rede Estadual de Educação de Minas Gerais. Em paralelo, atua como escritor e produtor audiovisual. É também membro do podcast "Conversê" do canal Sadtalkndplay. E-mail: profmatheusroedel@gmail.com. Orcid ID: http://orcid.org/0000-0002-8659-852X.
} 
Hill (1982). Considering the themes and writing style of John Fante in the novels discussed here, we can relate them to the experience of the marginal writer in an unfavorable situation: a not very promising future in a country that is experiencing a recessionary economic scenario. Forged for the writing, Bandini is configured as a kind of author's mirroring, a character in which Fante inserts himself through time and narrative within the scope of autobiographical writing.

Keywords: alter ego; Arturo Bandini; John Fante; self-writing; Literature written in English 


\section{Introdução}

Ao dissertar sobre o surgimento do romance como um gênero tipicamente burguês, Ian Watt (1990) esclarece que este teve como principal característica o rompimento das convenções da tradição em prol do sujeito. Portanto, para o autor "o primeiro grande desafio a esse tradicionalismo partiu do romance, cujo critério fundamental era a fidelidade à experiência individual - a qual é sempre única e, portanto, nova" (WATT, 1990, p. 15).

Nesse sentido, John Fante destaca-se por nos apresentar uma obra permeada de questões e temáticas intragáveis para a sociedade da época, a década de 1930 nos Estados Unidos. Importante esclarecer que um dos aspectos que corrobora a classificação da obra de Fante como intragável, no que tange ao "rompimento das tradições", é a apresentação, em seus romances, da aspereza de situações, assim como a crueza da vida marginal, expondo representações do que há de mais negativo na vida das grandes cidades.

Rumo a Los Angeles (1989), por exemplo, do autor ítalo-americano, só foi publicado após sua morte. Consequentemente, essa foi a primeira aparição do famoso personagem Arturo Bandini, objeto de análise deste trabalho.

Em 1933, Fante começou a trabalhar no romance. O cenário: os Estados Unidos pós-quebra da bolsa de Nova York, ainda com uma guerra pela frente. Ao terminar o livro, três anos mais tarde, previu o incômodo que a obra causaria:

Em 1933 John Fante morava num sótão em Long Beach e escrevia seu primeiro Romance, Rumo a Los Angeles. "Tenho sete meses e 450 dólares pra escrever meu primeiro romance. Na minha opinião é mais que razoável", disse Fante numa carta a Carey McWilliams, em 23 de fevereiro de 1933. Tinha assinado um contrato com a editora Knopf e recebera um adiantamento, mas não terminou o romance em sete meses. Em 1936 reescreveu as primeiras cem páginas e encurtou um pouco o livro, terminando o romance. Numa carta a McWilliams (c. 1936) Fante escreveu: "Rumo a Los Angeles está pronto - rapaz, como estou contente! Espero enviar o manuscrito na sexta-feira. Certas partes vão queimar o traseiro de muita gente. Talvez seja muito forte, isto é, falta 'bom gosto'. Mas isso não me preocupa". O romance nunca foi publicado, provavelmente porque o tema foi considerado provocante demais nos anos 30 (Nota editorial de Rumo a Los Angeles, 1989, s.p.). ${ }^{1}$

Como podemos perceber, na nota editorial da edição brasileira de Rumo a Los Angeles, de 1989, de fato, a publicação não saiu, provavelmente pelo caráter provocador do tema e do tom narrativo, fazendo com que o recorrente Arturo Bandini só fosse apresentado ao público em 1938, em Espere a Primavera, Bandini.

Em "Elementos de uma crítica 'vulgar' das críticas 'puras", Pierre Bourdieu reflete sobre o desprestígio da chamada escrita "vulgar", "fácil”, em relação ao privilégio gozado pela escrita culta e canônica:

Correndo o risco de parecer adaptar-se aos "efeitos fáceis" estigmatizados pelo "gosto puro", seria possível mostrar que toda a linguagem da estéti- 
ca está confinada em uma rejeição pelo princípio do fácil, entendido em todos os sentidos atribuídos a esta palavra pela ética e estética burguesas; que o "gosto puro", puramente negativo em sua essência, tem por princípio a aversão, frequentemente designada como visceral ("faz adoecer" e "provoca vômitos"), por tudo o que é "fácil", como se diz de uma música ou de um efeito estilístico, assim como de uma mulher ou de seus costumes. (...) De acordo com as palavras usadas para denunciá-las, "fácil" ou "ligeiro", e, é claro, mas também "frívolo", "fútil", "espalhafatoso", "superficial", "sedutor" (traduzido, em inglês, para o termo mais distinto, meretricious) ou, no registro das satisfações orais, "xaroposo", "adocicado", "insosso", "enjoativo", as obras "vulgares" não são somente uma espécie de insulto ao requinte dos requintados, uma maneira de ofensa ao público "difícil" que não entende que lhe ofereçam coisas "fáceis" (...) tais obras suscitam o mal-estar e a aversão ao adotarem métodos de sedução, habitualmente denunciados como "baixos", "degradantes", "aviltantes", que incutem no espectador o sentimento de ser tratado como qualquer um, que se pode seduzir com atrativos de pacotilha, convidando-o a regredir para as formas mais primitivas e elementares do prazer, quer se trate das satisfações passivas do gosto infantil pelos líquidos doces e adoçados (evocados pelo termo "xaroposo") ou das gratificações quase animalescas do desejo sexual (BOURDIEU, 2013, p. 449).

Nessa perspectiva, é possível compreender a receptividade tardia de sua literatura, uma vez que mostra a realidade crua daqueles que vieram em busca do American Dream. John Fante está inserido, portanto, no seleto grupo de escritores outsiders, rejeitados/censurados pela sociedade norte-americana, em seu conservadorismo político e religioso, por sua forma ácida de narrar a vida que pulsa longe da alta sociedade - no que tange a intelectualidade artística dos escritores - à qual o seu personagem, Arturo Bandini, tem ânsias de ascender. Nessa perspectiva, trabalhar com a obra de John Fante nos permite explorar aspectos como a escrita marginal, que posteriormente vieram a ser desenvolvidos por outros escritores, como por exemplo, Charles Bukowski, considerado responsável por resgatar Fante.

John Fante produziu quatro romances cujo contexto é o da Grande Depressão americana e nos quais o protagonista é Arturo Bandini: Wait Until Spring, Bandini (1938), The Road to Los Angeles (cronologicamente este é o primeiro romance da saga, mas foi publicado apenas postumamente em 1985), Ask the Dust (1939) e Dreams from Bunker Hill (1982). No Brasil, respectivamente: Espere a Primavera, Bandini (1990), Rumo a Los Angeles (1989), Pergunte ao Pó (1984) e Sonhos de Bunker Hill (1985). As obras que compõem essa "saga" foram selecionadas para este trabalho justamente pela escolha de John Fante em manter o mesmo protagonista: Arturo Bandini.

Alguns trabalhos sobre a obra de John Fante enveredam-se pelo caminho da autoficcionalidade ao explorarem as possíveis aproximações entre o personagem Arturo Bandini e seu criador. Todavia, este trabalho buscará defender que tais aproximações classificariam a obra de John Fante como narrativas ou romances autobiográficos e não como autoficções, pois há sutis diferenças entre essas possibilidades de escrita de si. 


\title{
2 Autoficção ou romance autobiográfico: singularidades
}

Ao transpor o mundo real para o mundo da representação, a obra literária despoja-o de sua contingência e torna-se simulacro. O processo de escrita literária, então, singulariza relações e processos frente às demais aplicações e usos da linguagem. Na trama da linguagem literária, dentre as diversas possibilidades de escrita surgem virtualidades a serem seguidas, como, por exemplo, a experiência do vivido, ou seja, a escrita de si. A menção à especificidade da linguagem literária evoca aqui a percepção de que estamos lidando com uma linguagem que nada deve à veracidade.

\begin{abstract}
Se algum desses elementos não corresponde, o livro é considerado ficção. O pacto autobiográfico se opõe ao pacto ficcional. Em uma autobiografia, o autor se comporta como um historiador ou jornalista, com a diferença de que a matéria de seu relato é ele mesmo. Se o leitor percebe que o autor esconde ou manipula a verdade, conclui que está mentindo, até porque as informações podem ser verificadas. $\mathrm{O}$ mesmo não pode ser dito de um romance, que opera no campo da ficção (LIMA, 2018, p. 190).
\end{abstract}

Leonor Arfuch $(2010)^{2}$, em sua obra O espaço biográfico: dilemas da subjetividade contemporânea, apresenta uma visão reformulada da proposta por Philippe Lejeune. Em O Pacto Autobiográfico, publicado pela primeira vez em 1975, o francês Philippe Lejeune atribuiu ao gênero autobiográfico a definição de "narrativa retrospectiva em prosa que uma pessoa real faz de sua própria existência, quando concentra sua história individual, em particular a história de sua personalidade" (LEJEUNE, 2008, p. 14). Segundo a autora, Lejeune define o espaço biográfico como um reservatório das formas diversas em que as vidas se narram e circulam, algo que a autora vê como uma definição sumária.

Para a autora argentina, a multiplicidade das formas que compõem o espaço biográfico oferece um traço em comum: elas contam, de diferentes modos, uma história ou experiência de vida, inscrevendo-se, assim, numa das grandes divisões do discurso: a narrativa. E, ao falar de narrativa, a autora logo inicia a sua reflexão sobre "identidade narrativa". Para refletir sobre essa questão, Arfuch retoma o "princípio dialógico e o conceito de polifonia" de Bakhtin, que ela considera uma virada capital quanto à consideração das "vozes" do relato. Mikhail Bakhtin constata nos romances de Dostoiévski "a multiplicidade de vozes e consciências independentes e imiscíveis e a autêntica polifonia de vozes plenivalentes" ou seja, "plenas de valor", já que "mantêm com as outras vozes do discurso uma relação de absoluta igualdade como participante do grande diálogo" (BAKHTIN, 2002, p. 4).

Nesse ínterim, Arfuch (2010) reflete sobre a seguinte questão:

se a descoberta do princípio dialógico bakhtiniano colocava em questão a unicidade da voz narrativa, como abordar o quem do espaço biográfico? Como se aproximar desse entrecruzamento das vozes, desses eus que imediatamente se desdobram não só num você, mas também em outros? Tan- 
to Lejeune, ao escolher a expressão de Rimbaud para o título de seu livro (Je est un autre), quanto Ricouer (Soi-même comme un autre) assinalam, nessa espécie de oximoro, o descentramento e a diferença como marca de inscrição do sujeito no decurso narrativo (ARFUCH, 2010, p.122 - grifos da autora).

Leonor Arfuch esclarece que essa marca é, antes de tudo, linguística. Referindo-se ao romance, a autora afirma que ele é o território privilegiado para a experimentação na medida em que pode operar no marco de múltiplos "contratos de veracidade", enquanto a margem se estreita no espaço biográfico, entre relato factual e ficcional.

\begin{abstract}
Mas, se os gêneros canônicos são obrigados a respeitar certa verossimilhança da história contada - o que não supõe necessariamente veracidade -, outras variantes do espaço biográfico podem produzir um efeito altamente desestabilizado, talvez como "desforra" diante de um excesso de referencialidade "testemunhal": as que, sem renúncia à identificação de autor, se propõe a jogar outro jogo, o de transtornar, dissolver a própria ideia de autobiografia, diluir seus umbrais, apostar no equívoco, na confusão identitária ou indicial [...]. Deslizamentos sem fim, que podem assumir o nome de "autoficção", na medida em que postulam explicitamente um relato de si consciente de seu caráter ficcional e desligado, portanto, do "pacto" de referencialidade biográfica (ARFUCH, 2010, p. 127).
\end{abstract}

Assim sendo, essa variedade de possibilidades de inscrição da voz narrativa no espaço biográfico, que vai das formas canônicas às menos discerníveis, dialogariam com a polifonia bakhtiniana, pois o que está em jogo não é, segundo a escritora argentina, uma política de suspeita sobre a veracidade ou a autenticidade da voz, ou seja, o "pertencimento", mas antes a aceitação do descentramento constitutivo do sujeito enunciador.

Ao realizar um estudo sobre a relação entre tempo e narrativa, na qual o narrador é o protagonista da própria história, Regina Dalcastagnè ressalta que a prática de tais narrativas tem um forte intuito de marcar a identidade e dotar de sentido a existência.

Por esse motivo,

muito longe de toda a teoria sobre a realidade e a nossa percepção dela, prosseguimos, na vida cotidiana, criando narrativas lineares, cronologicamente estruturadas, para darmos conta da nossa presença no mundo. Uma presença que envolve, basicamente, a experiência do tempo. [...] Daí as inúmeras histórias de vida, as narrativas biográficas, que tentam dar sentido à existência" (DALCASTAGNÈ, 2005, p. 113-114).

Todavia, o conceito de autobiografia é escorregadio, refletindo uma tendência a caracterizarmos como "autobiográfica" qualquer manifestação que apresente alguma similaridade com os fatos da história de vida do autor.

Por outro lado, segundo Anna Faedrich (2015) em seu artigo O conceito de autoficção: demarcações a partir da literatura Brasileira contemporânea, há uma 
especificidade que demarca o gênero autoficção: a ambiguidade. Para a autora, misturar realidade e ficção é uma condição estrita à autoficção e esta se encontra em romances históricos e em romances autobiográficos.

Mas então como saber se o romance autobiográfico é também autoficção? A diferença se dá, segundo a autora, em como isso é feito. Exemplificando com a obra O Ateneu, de Raul Pompeia, Faedrich (2015) esclarece que ela só pode ser classificada como autobiográfica por elementos extratextuais, ou seja, em nenhum momento informações do autor são sugeridas na tessitura da narrativa, nesse sentido, segundo a autora, Raul Pompeia não cria e não tem a intenção de criar um pacto de leitura marcado pela ambiguidade. "Já na autoficção, é necessária a intenção de abolir os limites entre o real e a ficção, confundir o leitor e provocar uma recepção contraditória da obra" (FAEDERICH, 2015, p. 49).

Dessa forma, é possível diferenciar a escrita autoficcional também pelo fato de nesta a ambiguidade ser potencializada pela atribuição de uma mesma nomeação às identidades do autor, do narrador e do protagonista, como faz Ricardo Lísias $(2012,2013)$ em O céu dos suicidas e Divórcio. As obras de Lísias operam dentro de um jogo de ambiguidade referencial (é ou não é o autor?) e de fatos (é verdade ou não? Aconteceu mesmo ou foi inventado?) que é estabelecido intencionalmente pelo autor.

Ainda segundo Faedrich (2015), não há dúvidas de que antes do neologismo “autoficção", autores já criavam esse pacto contraditório de leitura, sem ter um termo que o nomeasse; apesar de ser menos frequente no passado, o exercício autoficcional é anterior à sua formulação conceitual. De acordo com a autora, Doubrovsky insiste que se ele é o inventor do termo, não é, certamente, o "da coisa". Todavia, como esclarece Faedrich (2015), tal afirmação de Doubrovsky é tardia. Primeiramente, ele diz ter criado o conceito de autoficção para definir a sua própria prática literária - todos os seus romances seriam autoficcionais; inclusive, Fils (1977) seria o primeiro exemplo do gênero. Porém, com o passar do tempo e a repercussão do debate, o teórico francês foi flexibilizando seu discurso e relativizando suas asseverações. Por isso, podemos, hoje, falar numa "atualização do conceito de autoficção", tendo em vista as mudanças no discurso do próprio criador do neologismo.

\section{Arturo Bandini: entrecruzamentos entre o ficcional e biográfico}

Adotando, pois, o método de diferenciação entre as possibilidades de escrita de si propostos por Faedrich (2015), verificamos que a "saga" de Arturo Bandini não pode ser classificada como autoficção, pois só sabemos que fragmentos do autor John Fante estão literalizados na obra por meio de elementos extratextuais, ou seja, em nenhum momento informações do autor são sugeridas na tessitura da narrativa. Outro aspecto que também merece ser aqui comentado é que não coincidem nome de autor e nome de personagem e, o próprio personagem Arturo Bandini, apesar de apresentar o mesmo nome nas obras elencadas, cria um certa confusão no leitor, pois, apesar de sugerir uma 
saga ou continuidade de um livro para o outro, apresenta um núcleo familiar inconstante: pai morto, mãe, irmã (Mona), e tio Frank em Rumo a Los Angeles e o nome de Arturo Gabriel Bandini; pai (Svevo Bandini), mãe (Maria Toscana), três filhos (Arturo, August e Frederico) e sogra (Donna Toscana) dois tios maternos em Espere a primavera, Bandini; pai e mãe distantes, epistolares e anônimos em Pergunte ao pó; e pai, mãe e dois irmãos menores (Mário e Tom) e uma irmã (Stella) em Sonhos de Bunker Hill.

Optamos pela denominação de "saga" (entre aspas), pois apesar da pretensa e insistente presença desse personagem nas obras, podemos depreender que o autor, talvez, não possuísse um plano de obra. Por isso essas mudanças na estrutura familiar. Acreditamos que não existia um projeto de tetralogia, mas uma insistente necessidade de colocar Arturo como uma contingência. Contudo, algo que esclarece essa inconstância é o fato de Rumo a Los Angeles, romance de estreia do alter ego, por exemplo, só ter sido publicado postumamente, assim como Sonhos de Bunker Hill. Outro fato que contribui para essa inconstância é que John Fante não é apenas autor desses romances. Durante sua vida, Fante enveredou, também, na escrita de romances, contos e novelas, além de roteiros para Hollywood. Ou seja, sua escrita não era linear, apesar da presença de um personagem jovem, descendente de imigrantes italianos, se configurar enquanto uma constante em sua obra ficcional, mesmo que esses "outros" apresentem nomes distintos de Arturo Bandini.

Nesse ínterim, é relevante a leitura desta passagem do prefácio de Espere a primavera, Bandini escrito pelo próprio autor:

Agora que estou velho não consigo olhar em retrospecto para Espere até a Primavera, Bandini sem perder o seu rastro do passado. (...). Não posso imaginar que o que escrevi há tanto tempo possa me apaziguar como o faz esse meio sonho, e, no entanto, não sou capaz de forçar-me a abrir esse primeiro romance e relê-lo. Tenho medo, não suporto ser exposto pelo meu próprio trabalho. Mas disto estou certo: todas as pessoas da minha vida de letras, todas as minhas personagens podem ser encontradas nesse velho livro. Não existe mais nada de meu ali, apenas a lembrança de velhos quartos de dormir e o som dos chinelos de minha mãe andando na cozinha (FANTE, 1990, p. 7).

Como Fante sugere, todos os personagens estão ali naquela obra. Os personagens que passeiam pelo universo ficcional dos autores são sua matéria bruta, e ao escritor é permitido todo tipo de manejo: é possível descartá-los, reconfigurá-los, reaproveitá-los novamente ou simplesmente abortá-los, caso não faça sentido a presença deles ali.

Portanto, a manutenção de um mesmo círculo familiar não importa. A temática sempre girará em torno de um jovem ítalo-americano em busca de superar a pobreza e o preconceito. Algo que se assemelha à sua história pessoal, como pode ser verificado nas cartas de Mencken a Fante, respectivamente de 31 de agosto de 1932 e de 22 de maio de 1933. 
Tenho a sensação de que você faria melhor de não mais escrever sobre sua família, esse assunto parece ser uma verdadeira obsessão para você. (...) Porque não escrever histórias sobre outros indivíduos? A vida na Califórnia deveria te sugerir um grande número de ideias (FANTE; MENCKEN, 1991, p. 44 - tradução nossa). ${ }^{3}$

De um tempo a outro, deve um homem dizer o que tem no coração, mas isso não pode evidentemente ser publicado por uma revista (FANTE; MENCKEN, 1991, p. 58 - tradução nossa). ${ }^{4}$

A partir desses comentários de H. L. Mencken, editor de John Fante, percebemos que a questão familiar era um tema recorrente. E é a partir da temática familiar que todas as outras temáticas vão se instaurando.

A escrita de si, portanto, pode promover uma reflexão sobre o uso dos fragmentos de memória e recortes biográficos. O bricoleur surge, dessa forma, como metáfora para a compreensão e análise de algumas práticas da escrita de John Fante. O escritor em seu processo de criação e construção poética, assim como o bricoleur em seu processo de coleta e construção de um projeto, coloca algo de si mesmo. E "ao utilizar resíduos e fragmentos de acontecimentos, histórias de um indivíduo ou de uma sociedade, ele não só 'fala' com eles, como também conta por meio deles" (CORRÊA; FRANÇA, 2014, p. 234). Nesse sentido, ao utilizar resíduos e fragmentos da memória, histórias de si, de outros ou de uma sociedade, o escritor estaria realizando um processo de reapropriação e de ressignificação, e tal procedimento permite inferir que processos de elaboração criativa perpassam por modos de subjetivação.

Por conseguinte, ao buscarmos compreender o biográfico na literatura como escrita de si, objetivamos compreender em que medida tais fragmentos se apresentam literalizados. Dessa forma, procura-se indagar de que modo ou por meio de quais estratégias o "eu" trabalha no arranjamento desses fragmentos.

A vida de Arturo Bandini é mostrada no conjunto dos quatro romances, dentre os quais Rumo a Los Angeles, publicado postumamente por Joyce Fante, esposa do escritor, dá início à "saga" como uma tentativa de desenvolvimento desse alter ego. Em uma carta a H. L. Mencken em 10 março de 1936, Fante relata:

Este livro é também tão autobiográfico que o leitor poderá bem acreditar nele. Mas a realidade é muito diferente de meu romance, contido de um ponto de vista psicológico, ele é tão autobiográfico quanto possível. (...) Esse esforço se inscreve nas peregrinações de Arturo, o herói do livro. Ele é eu, e poderíamos dizer que eu sou ele (FANTE; MENCKEN, 1991, p. 124 - tradução nossa). ${ }^{5}$

Parte da ficção fanteana se cristaliza em volta do anti-herói Arturo Bandini, que vive desventuras às vezes trágicas, às vezes patéticas e sobretudo humanas. Arturo Bandini é um personagem representativo por ser considerado a projeção do autor, uma maneira como este se imagina e se escreve, cheio de defeitos tão humanos que fortalecem e criam este anti-herói. A título de exemplo, vejamos outro fragmento da carta a seu editor, Mencken, de 10 março de 1936: "Eu o 
(Arturo Bandini) acho muito representativo de meu tipo de jovem. (...) A história nos transformará, meu herói e eu, em imbecis, mas isso eu já sei bem antes que essa história seja escrita" (FANTE; MENCKEN, 1991- tradução nossa). ${ }^{6}$

Rumo a Los Angeles, primeira obra da "saga" de nosso anti-herói a ser escrita, traz como temática a história do jovem ítalo-americano, Arturo Bandini, que toma uma decisão que irá mudar sua vida: ser um escritor. Com a certeza da escrita, Arturo rouba as joias da mãe e após surrar a irmã única, Mona, parte rumo a Los Angeles. Este primeiro Arturo Bandini carrega em si a revolta da adolescência e a angústia do preconceito.

Comecei a trabalhar com fúria e eles riram e disseram que logo mais eu ia aprender umas coisinhas. A picareta e a pá começaram a ficar pesadas. Eu chupava minhas bolhas arrebentadas e tinha ódio daqueles homens. Um dia na hora do almoço me sentei, cansado, olhei minhas mãos e disse pra mim mesmo: "porque você não acaba com esse emprego antes que ele acabe com você?” (FANTE, 1989, p. 7).

Em Espere a primavera, Bandini, o narrador é uma voz impessoal que conta a história de Svevo e Maria Bandini, imigrantes italianos em Rocklin, Colorado, assolados pela miséria e o frio. Arturo Bandini é o primogênito da família. Nessa obra, Arturo, ainda que coadjuvante na trama, é quem assume um papel decisivo na resolução do conflito. O pai Svevo, após uma briga com a esposa, abandona a família no inverno para viver um caso com uma viúva rica. Arturo vai com seu cachorro Jumbo ao encontro do pai que não suporta ver seu filho (e a si próprio) serem ofendidos pela amante, a viúva Hildegarde:

- Seu monstrinho desprezível - Disse a viúva. - Svevo Bandini, você vai permitir que esse menino horrível continue se comportando desse jeito?

- Arturo! - Bandini disparou.

- Seus camponeses! - disse a viúva - Estrangeiros! Vocês são todos iguais, vocês e seus cachorros e tudo mais.

Svevo cruzou a grama até a viúva Hildegarde. Falou com firmeza tranquila:

- Mrs. Hildegarde. - disse. - Esse é meu filho. A senhora não pode falar com ele desse jeito. Esse menino é americano. Ele não é estrangeiro.

- Eu estou falando com você também! - disse a viúva.

- Bruta animale! - disse ele - Puttana!

Ele cobriu o rosto dela com saliva.

- Você é um animal! - disse ela. - Animal!

Bandini dirigiu-se para Arturo.

- Venha - disse. - Vamos para casa (FANTE, 1990, p. 178).

O Arturo Bandini de Pergunte ao pó é um jovem escritor que sonha com o sucesso. Poderíamos definir esse Bandini como um jovem com pouco dinheiro no bolso, pouca experiência, muita garra, talento e muitos conflitos. Segundo prefácio do tradutor Paulo Leminski, Pergunte ao pó é o 
retrato do artista quando jovem e tolo o bastante para se julgar o melhor escritor do mundo, Ask the dust. Abre um movimento complexo no interior de seu processo. Afinal, é a história das desventuras de alguém querendo ser um grande escritor: o relato sobre o próprio escrever, desvelando seu fazimento (LEMINSKI, 1987, s.p.).

E ainda:

O fluxo verbal da prosa de Fante é afetado por aquele grau de imprevisibilidade, a que associamos o nome de poesia. Só com técnicas narrativas, aliás, não teria atingido o agudo da pungência, docemente lírico, e amargamente cínico, que caracteriza sua narrativa, entremeada de ex-abruptos dramáticos, mas contidos (LEMINSKI, 1987, s.p.).

Em Pergunte ao Pó, Arturo Bandini vive um amor turbulento com Camila Lopes, garçonete mexicana do Angel's flight. Uma relação amorosa cheia de preconceitos e agressões mútuas:

Apoiei a revista no balcão e apaguei a dedicatória para a Princesa Maia. Em seu lugar, escrevi:

\section{Cara Sapatos Esfarrapados:}

Pode não saber disso, mas na noite passada você insultou o autor desta história. Sabe ler? Se souber, invista quinze minutos do seu tempo e deleite-se com uma obra prima. E da próxima vez seja cuidadosa. Nem todo mundo que vem a este antro é um vagabundo.

Arturo Bandini

(FANTE, 2003, p.47)

Sonhos de Bunker Hill é o último livro escrito por Fante. Escrito não, ditado. Fante, nesse momento de sua vida, havia amputado as duas pernas e perdido a visão por causa da diabetes e, para continuar vivo, ditou para a esposa, Joyce Fante, uma última história de Arturo Bandini, prefaciada na edição brasileira por Caio Fernando Abreu.

Em volta de Bandini, uma galeria de personagens - muitas nitidamente calcadas em modelos reais daquela fauna absurda dos anos de ouro de Hollywood, nas décadas de 30 e 40 - tão malucas quanto ele. [...] Em todos, a palavra de Fante não demarca nenhum limite definido entre a dignidade e o grotesco. Nessa delicada faixa de transição do cômico para o trágico, nessa corda-bamba entre o que se gostaria de ser e o que realmente se é, equilibram-se as pungentes criaturas de Fante. Que fazem rir de nervoso, de olhos molhados. [...]

Em todos os tombos de Bandini, o desmentido da fantasia de que a vida, afinal, seja menos mesquinha. Viver, a própria vida vai provando aos pouquinhos, não tem nenhum happy-end em technicolor e cinemascope.

Para Fante-Bandini, a única forma de conquistar essa ilusão de sentido, grandeza ou beleza da vida talvez tenha sido escrever (ABREU, 1987, p. 8). 
Sonhos de Bunker Hill encerra a última narrativa da vida de Arturo Bandini, que entra no mercado cinematográfico do esplendor de Hollywood e se decepciona com a crueldade dessa fábrica de sonhos:

Todo meu trabalho, tudo quanto eu havia pensado, estava tão distante do filme que era espantoso, inacreditável. Só em dois lugares reconheci frases que possivelmente eu teria escrito e o diretor não tinha riscado. A primeira era numa cena do começo, quando o xerife corria para Sun City a todo galope e parava o cavalo em marcha no salão gritando: "Whoa!" lembrava daquela frase: “Whoa!". Era minha. Mais adiante, o xerife saía arrogante do salão, montava seu cavalo e gritava: "À toda!". Era frase minha também.: "À toda!". Whoa e à toda - minha contribuição para o roteiro (FANTE, 1987, p. 101).

Nesse sentido, esse outro (Bandini) forjado para a escrita é um espelhamento do autor, um personagem alter ego na qual Fante se insere através do tempo e da narrativa. Ou seja,

a personagem Arturo Bandini é ideal de Fante, como ele retrata a si e a outros na sua escrita. Sabia que suas histórias não tinham muitas pretensões mais do que, resgatar do pó do esquecimento figuras que, se ele não tivesse lembrado, permaneceriam para sempre anônimas. (ABREU, 1987, p. 9).

Embora Arturo Bandini apresente-se como um desdobramento do autor, ou seja, um personagem de si próprio, este recebe sonhos, destila preconceitos, sofre as mesmas dores do autor e do leitor, a ponto de este último se identificar com suas confusões e com sua maneira tortuosa, mas verossímil, de lidar com as desaventuras da vida.

\section{Temas recorrentes na saga de Arturo Bandini: um breve estudo comparado}

As quatro obras de John Fante aqui elencadas possuem evidentemente algumas afinidades temáticas, como o conflito familiar. A relação difícil com o pai e a figura sofrida da mãe, católica fervorosa, são constantes e/ou pulsantes mesmo quando não explicitadas. A obra de Fante também apresenta como temáticas o conflito entre raças, credos, valores e o conflito interno da busca, do vir a ser. Todos esses conflitos estão trespassados pelo fato de ser filho de imigrantes italianos em continente americano. A religiosidade inerente à cultura e seu conflito quase barroco entre o sagrado e o profano; o conflito com a família da qual ora sente orgulho, ora sente vergonha; o ser americano de nascimento, mas ser tachado de Carcamano, o se vangloriar por ser americano e tratar os outros de maneira xenofóbica para se sentir menos inferior; e o querer ser alguém em a busca do tão desejado American Dream: se tornar um escritor, se tornar reconhecido, se tornar alguém, vir a ser, devir... Tais aspectos abrem espaço para o estudo da 
subjetividade construída nos enredos, convidando-nos a examinar estas obras a partir do mergulho dentro das relações e do discurso do "estrangeiro" no âmbito das representações literárias.

Em Tocata e fuga para o estrangeiro, Julia Kristeva (1994) fala sobre o "estrangeiro". Para a autora:

A rejeição de um lado, o inacessível do outro: se tiver forças para não sucumbir a isso, resta procurar um caminho. Fixado a esse outro lugar, tão seguro quanto inabordável, o estrangeiro está pronto para fugir. Nenhum obstáculo o retém e todos os sofrimentos, todos os insultos, todas as rejeições lhe são indiferentes na busca desse território invisível e prometido, desse país que não existe mas que ele traz no seu sonho e que deve realmente ser chamado de um além (KRISTEVA, 1994, p.13).

Dos vários sentimentos que podemos verificar no relato do personagem Arturo Bandini, poderíamos inferir que o de rejeição e a sensação de estranhamento encontram-se atrelados a alguns estigmas, como o de ser de família pobre e descendente de imigrantes. Nesse sentido, a ideia de deslocamento, inicialmente associada ao aspecto geográfico-político, possui aqui outras implicações. Assim, deslocado, emigrado, exilado, em terra estranha, estranho, estrangeiro são algumas palavras usadas para indicar essas nuances. Nos textos literários em questão, as referências a esse "sentimento de deslocamento" promovem um leque de representações variadas e que tangenciam também a construção identitária do personagem, que poderíamos resumir como aquele que busca. Bandini busca insistentemente se desgarrar de tudo o que lhe remete à sua condição de pobreza, à sua herança católica e italiana, ao pensamento e à dimensão tacanha de sua existência. E para se livrar dessa bolha a que poderia ter sucumbido, enfrenta a tudo e a todos, para se tornar alguém, para se tornar um escritor em uma jornada megalomaníaca.

Em Espere a Primavera, Bandini, Arturo é retratado em todas as suas nuances e contrastes, conflitos e ânsias:

Seu nome era Arturo, mas ele o detestava e queria se chamar John. Seu sobrenome era Bandini, ele queria que fosse Jones. Sua mãe e seu pai eram italianos, mas queria ser um americano. Seu pai era pedreiro, mas ele queria ser arremessador de beisebol do Chicago Cubs. Eles moravam em Rocklin, Colorado, população dez mil, mas queria morar em Denver, a cinquenta quilômetros dali. Tinha sardas no rosto, mas gostaria de não ter. frequentava uma escola católica, mas queria ir a uma escola pública. Era coroinha, mas era também um demônio e odiava os coroinhas. Ele queria ser um bom menino, mas tinha medo disso porque assustava-se com a ideia de que seus amigos o chamassem de bom menino. Ele era Arturo e amava o pai, mas vivia apavorado com o dia em que cresceria e seria capaz de surrar aquele mesmo pai. Ele idolatrava o pai, mas achava a mãe boba e maricas. [...] Ele tinha catorze e a descoberta de que sua própria mãe não o excitava fazia com que ele a odiasse secretamente. Observava sua mãe, sempre com o rabo do olho. Ele a amava, mas também a odiava (FANTE, 1990, p. 23-24). 
O Arturo de Rumo a Los Angeles se chama Arturo Gabriel Bandini. É um jovem pretensioso que vive com a mãe e a irmã Mona e com as quais tem uma relação conflituosa por elas não levarem seu plano de se tornar um escritor a sério. Bandini passa por vários empregos braçais e não se fixa em nenhum deles, pois considera todos eles indignos: "Arturo, eu disse, este emprego tem um futuro muito limitado; por que você não larga isso hoje mesmo? Por que não manda esse cozinheiro se foder?” (FANTE,1989, p. 8) e também porque sempre arrumava confusão por onde passava: “- Não importa. Pode ser cinco centavos, pode ser vinte e cinco; considerando as circunstâncias, não importa em absoluto. Sou, como já lhe disse, um escritor. Eu interpreto a cena americana, estou aqui para coletar materiais para meu novo livro" (FANTE, 1989, p. 51). A partir dessa obra, Bandini já aparece como narrador-personagem, em constante reflexão sobre si mesmo em seus monólogos interiores.

- Cadê a Mona? - perguntei.

- Tá na igreja.

- Minha própria irmã reduzida à superstição das preces! Sangue do meu sangue. Uma carola, uma beata! Que barbárie!

- Não comece com essas histórias de novo. Você é um moleque que lê demais, só isso.

- É o que você pensa! É absolutamente óbvio que a senhora tem complexo de fixação.

Ela empalideceu.

- Tenho o quê?

- Esqueça. Não adianta falar com caipiras, rústicos, seres irracionais. O homem inteligente tem certas reservas quanto à escolha de seus ouvintes. (FANTE, 1989, p. 15)

Levantei o punho e deixei-o voar. Pegou ela na boca. Ela pôs a mão nos lábios e caiu em cima do travesseiro. Minha mãe entrou aos gritos. O sangue escorria entre os dedos de Mona.

- Quer dizer que você riu do livro, é? Você caçoou! Caçoou do trabalho de um gênio! Você! Zombou de Arturo Bandini! Pois agora Bandini contra-ataca. Em nome da liberdade (FANTE, 1989, p. 140).

No primário os moleques me enchiam o saco me chamando de gringo, de carcamano e macarrone. Doía todas as vezes. Era horrível. Eu me sentia uma porcaria, tão infeliz, tão indigno. E sabia que aquilo ia doer no filipino também.

$[\ldots]$

Resolvi repetir a dose com o filipino:

- Você não é negro, não. Você é um bosta dum filipino, o que é pior ainda. Só que a cara dele não tava mais morena nem negra: tava roxa.

- Um filipino amarelo! Um bosta dum oriental, um estrangeiro! Você não se sente mal de ficar perto de gente branca? (FANTE, 1989, p. 59).

Tive vontade de rezar. Não fazia uma oração há dois anos - desde que saí do ginásio e comecei a ler daquele jeito. Mas agora queria rezar de novo, tinha certeza que ia ajudar, que me faria me sentir melhor, pois quando era garoto rezar sempre tinha esse efeito.

[...]

Não haveria de ser o padre-nosso, aquela história do Pai Nosso que estais 
no Céu, santificado seja Vosso nome, venha a nós o Vosso reino... Eu não acreditava mais naquilo. Não existia céu nenhum; talvez houvesse um inferno, parecia muito possível; mas céus não havia nenhum.

[...] Havia Nietzsche, Friedrich Nietzsche.

Tentei ele também.

Rezei: "Oh, meu amado Friedrich!"

Não adiantou. Parecia que eu era homossexual.

Tentei de novo:

'Oh, meu caro Sr. Nietzsche!'

Pior. Lembrei do retrato de Nietzsche que vinha no frontispício dos seus livros. Parecia um garimpeiro dá época da Corrida do Ouro, com aquele bigodão descabelado, e eu detestava aqueles pioneiros.

[...]

Depois de pensar em tanta gente, sem resultado, cansei. Já estava prestes a abandonar a coisa toda quando de repente tive uma boa ideia. A ideia era a seguinte: eu não devia rezar para deus nem para os outros, mas pra mim mesmo.

"Arturo, meu rapaz. Meu bem-amado Arturo. Vejo que você sofre tanto, e tão injustamente. Mas você é corajoso, Arturo. Você me lembra um poderoso guerreiro, com as cicatrizes de um milhão de conquistas. Que coragem você tem! Que nobreza! Que beleza! Ah, Arturo, como você é belo, realmente belo! Eu te amo tanto, meu Arturo, meu grande e poderoso deus. Pois chore agora, Arturo. Deixe que suas lágrimas escorram, pois sua vida é uma vida de luta, uma amarga batalha até o embate final, e ninguém sabe disso a não ser você, ninguém exceto você, um galhardo guerreiro que luta sozinho, firme e resoluto, sem fraquejar, um grande herói como o mundo jamais conheceu" (FANTE, 1989, p. 100-102).

Na terceira obra, Pergunte ao Pó, Arturo Bandini é um jovem adulto de 20 anos, determinado, porém angustiado, procurando a si mesmo na escrita, na vida e no amor. A obra transparece uma continuidade em relação à obra anterior, Rumo a Los Angeles, como se o adolescente, agora jovem adulto, Bandini, narrasse a sua empreitada como jovem escritor morando no Alta Loma Hotel, um hotel que não aceitava nem mexicanos, nem judeus.

Então você caminha ao longo de Bunker Hill e sacode o punho para o céu e eu sei o que está pensando Bandini. Os pensamentos de seu pai antes de você, fustigam-lhe as costas, esquentam-lhe a cabeça, e a culpa não é sua: este é o seu pensamento, que você nasceu de pais miseráveis, pressionados porque eram pobres, fugiu da sua pequena cidade do Colorado porque era pobre, perambula pelas sarjetas de Los Angeles porque é pobre, esperando escrever um livro para ficar rico, porque aqueles que o odiavam lá no Colorado não vão odiá-lo se escrever um livro. Você é um covarde, Bandini, um traidor de sua alma, um péssimo mentiroso diante do seu Cristo ensanguentado. É por isso que escreve, é por isso que seria melhor se você morresse (FANTE, 2003, p. 21).

Deus Todo-Poderoso, lamento que agora eu seja ateu, mas o Senhor leu Nietzsche? Ah, que livro! Deus Todo-Poderoso, vou jogar limpo nesta questão. Vou Lhe fazer uma proposta. Faça de mim um grande escritor e eu voltarei à Igreja. Eu Lhe peço, caro Deus, mais um favor: faça minha mãe feliz. Não me importo com o Velho; ele tem seu vinho e sua saúde, mas minha mãe se preocupa tanto. Amém (FANTE, 2003, p. 24). 
- Você se esforça tanto para ser uma americana - falei. Por que faz isto? Olhe para si mesma.

Foi até o espelho e estudou-se gravemente.

- Estou cansada - disse. - Tivemos uma noite agitada.

- São esses sapatos - falei. - Devia calçar o que seus pés foram feitos para calçar: huaraches. E toda essa pintura no seu rosto. Está péssima: uma imitação barata de uma americana. Está desgrenhada. Se eu fosse um mexicano, arrancava sua cabeça. É uma desgraça para sua gente.

- Quem é você para falar assim? - disse. - Sou tão americana quanto você. Ora, você não é americano coisa nenhuma. Veja sua pele. É moreno como os carcamanos. E seus olhos são negros (FANTE, 2003, p. 152).

O Arturo de Sonhos de Bunker Hill é um roteirista, ou pelo menos tenta se tornar um. Todavia, o que acaba acontecendo é que ele trabalha revisando roteiros de outros, o que o deixa em segundo plano. Nesta obra, ao contrário da exótica Camila Lopes, de Pergunte ao pó, sua relação amorosa, também conflituosa, é com Helen Brownell, a dona da pensão em que ele morava, uma mulher contida e madura.

Sentado no meu escritório eu me aborrecia pensando no quanto ela era velha, cinco anos mais velha que minha própria mãe; eu tinha ânsia de vômito e tossia para expulsar aquela sensação desagradável. Pensava no rosto dela, as pequenas linhas em volta dos olhos, os sulcos no pescoço, a bunda muito pequena, os vestidos longos demais, o estalido dos joelhos quando sentava, as bochechas encovadas quando tirava a dentadura, seus pés frios, suas velhas maneiras do Kansas. [...] Estava errado em gastar meus melhores anos com uma mulher velha que só me dava velhos pensamentos em troca (FANTE, 1987, p. 51).

A infância de Arturo é retomada na descrição durante um relato memorialístico: o menino sardento, o pai alcoólatra e empreiteiro de obras, a educação em colégio católico. Todavia, os empregos foram menos braçais que os descritos em Rumo a Los Angeles. No entanto, permanece a rotatividade dos empregos e as idas à biblioteca. A religiosidade conturbada também é uma constante,

Murmurei uma Ave-Maria e fui interrompido por Thelma Farber. Ave Maria cheia de graça e Thelma Farber nua em meus braços. Santa Maria, Mãe de Deus, eu beijando os peitos de Thelma Farber, apalpando seu corpo e correndo minhas mãos por suas coxas. Rezai por nós pecadores, agora e na hora de nossa morte - e meus lábios moviam-se até os quadris de Thelma e eu a beijava extasiado. Eu estava louco me contorcendo. Sentia meu corpo ajoelhado ali, a rigidez dos meus quadris, a ponto de uma ereção, o absurdo daquilo, a dicotomia enlouquecedora. Levantei-me e sumi de lá, desci para o carro e fui dirigindo amedrontado, trêmulo, ridículo (FANTE, 1987, p. 59).

Tal qual os outros Arturos, esse Arturo também quer ser reconhecido. E quando consegue ter seu nome vinculado a uma obra, um roteiro, preferiu recusar o crédito, pois todo o seu texto havia sido modificado a ponto de as únicas palavras reconhecida por ele serem "Whoa" e "à toda". Em Sonhos de Bunker Hill 
fica mais pulsante a sua busca por reconhecimento, pois ele já está um pouco mais maduro e já consegue, minimamente, trabalhar com a escrita, mesmo que ainda seja mais como revisor. O vir a ser é o grande conflito. Ora se enaltece, ora duvida de sua capacidade.

Fui para a máquina e sentei diante dela. Minha ideia era escrever uma frase, uma única frase perfeita. Se pudesse escrever uma frase boa, escreveria duas, e se pudesse escrever duas, escreveria três, e se pudesse escrever três, escreveria para sempre. Mas e se eu falhasse? E se eu tivesse perdido meu belo talento? E se ele tivesse se queimado no fogo do Biff Newhouse esmurrando meu nariz ou em Helen Brownell morta para sempre? O que aconteceria comigo? Voltaria para Abe Marx e seria um ajudante de garçon de novo? Tinha dezessete dólares e o medo de escrever (FANTE, 1987, p. 115).

Considerando as temáticas e o estilo de escrita de John Fante nos romances aqui discutidos, podemos relacioná-los à experiência do escritor marginal em um panorama nada favorável: um futuro pouco promissor em um país que amarga um cenário econômico recessivo. As obras podem ser entendidas, portanto, como um retrato da precária condição do indivíduo proveniente de classes menos favorecidas em uma tentativa desesperada de mudar sua realidade.

\section{Considerações Finais}

Vimos ao longo deste trabalho que a escrita de cunho autobiográfico privilegia uma visão particularizada da realidade. Adotando, pois, o modelo de diferenciação entre as possibilidades de escrita de si propostos por Faedrich (2015), verificamos que a saga de Arturo Bandini não pode ser classificada como autoficção, pois só sabemos que fragmentos do autor John Fante estão literalizados na obra por meio de elementos extratextuais.

No caso das obras aqui discutidas, percebemos que Arturo Bandini é quem encena a sua "verdade" dentro do texto de John Fante. Bandini, enquanto simulacro da figura do escritor, escancara toda a presunção desse sujeito, assim como toda a angústia de não ser bom, de não ser aceito, de ser uma farsa. Talvez estivesse John Fante rindo de si mesmo. Um riso nervoso. Um riso que fica no limbo entre a compaixão e a repugnância por esse personagem configurado pelo lado de fora da margem.

Um personagem descentrado, no limbo, no entrelugar, que se orgulha de ser americano, mas cuja ascendência italiana marca com o estigma de "carcamano". Bandini não quer ser estrangeiro e não quer ser visto com imigrantes, achando que isto o torna mais estadunidense, mas por outro lado é desprezado pelos americanos, visto que, entre eles, há uma tradição em separar os indivíduos pela origem e pela tonalidade de pele, como se o continente americano não tivesse sido constituído pela colonização.

Bandini pretende construir para si a imagem de um escritor de sucesso, pautada na herança daqueles autores que ele admira, tentando diferenciar-se dos 
demais jovens de seu convívio assim como de seus entes familiares: como um sujeito letrado. Uma tentativa de fugir da herança de seu pai, um funcionário da construção civil.

Assim, poderemos inferir que Bandini constitui-se enquanto uma metáfora da luta do escritor por um lugar ao sol nas grandes metrópoles e também do sonho americano de ascensão, que o plano da realidade teima em jogar por terra.

Por fim, neste trabalho, ao discutir o biográfico na literatura, objetivamos compreender por meio de quais estratégias o "eu" trabalha no arranjamento desses fragmentos na escrita de si.

\section{Notas}

1. A presente nota editorial não deixa transparecer o nome de quem a escreveu. Ela está assinada pelas iniciais J. C.

2. Discussão sobre essa obra também consta em outro artigo redigido em parceria com Elton Mendes Francelino, disponível em: http://www.ileel.ufu.br/ anaisdosilel/wp-content/uploads/2014/04/silel2011_874.pdf.

3. No original: "J'ai le sentiment que vous feriez mieux de ne plus écrire sur votre famille. Ce sujet semble être une véritable obsession à vos yeux. (...) Pourquoi ne pas écrire des nouvelles sur d'autres individus? La vie en Californie devrait vous suggérer um grand nombre d'idées."

4. No original: "De temps, à autre, il faut qu'un homme disse ce qu'il a sur le coeur, mais cela ne peut évidemment pas être publié par une revue."

5. No original: "Ce livre est aussi autobiographique que le lecteur voudra bien le croire. Mais la réalité est três diferente de mon roman. Néanmois, d’un point de vue psychologique, cela est aussi autobiographique et sincère que possible".

6. No original: "Cet effort s'inscrit dans les pérégrinations d’Arturo, les héros du livre. Il est moi, et l'on pourrait dire que je suis lui. Je le crois trés représentatif de mon type de jeune homme. (...) L'histoire nous transformera, mon héros et moi, em imbéciles, mais je sais cela bien avant que cette histoire soit écrite."

\section{Referências}

ARFUCH, L. O espaço biográfico: dilemas da subjetividade contemporânea. Tradução de Paloma Vidal. Rio de Janeiro: EDUERJ, 2010.

BAKHTIN, M. Problemas da Poética de Dostoiévski.Tradução de Paulo Bezerra. Rio de Janeiro: Forense Universitária, 2002.

BOURDIEU, P. Post Scriptum: Elementos de uma crítica "vulgar" das críticas "puras". In: BOURDIEU, P. A Distinção: Crítica Social do Julgamento. Tradução de Daniela Kern, Guilherme J. F. Teixeira. 2a Ed. 1ª Reimpressão. Porto Alegre: Zouk, 2013. p. 448-502.

CORRÊA, M. R; FRANÇA, C. A figura do bricoleur em práticas artísticas. Visualidades, Goiânia, v.12, n.2, p. 225-239, jul-dez 2014.

DALCASTAGNĖ, R. Vivendo a ilusão biográfica. A personagem e o tempo na narrativa brasileira contemporânea. Literatura e sociedade, São Paulo, n. 8, p. 112125, 2005.

DOUBROVSKY, S. Fils. Paris: Galilée, 1977. 
FAEDRICH, A. O conceito de autoficção: demarcações a partir da literatura brasileira contemporânea. Itinerários, Araraquara, n. 40, p. 45-60, jan./jun. 2015. Disponível em: https://periodicos.fclar.unesp.br/itinerarios/article/view/8165/5547. Acesso em: 14 fev. 2020.

FANTE, J. Ask the Dust. 1939. Santa Rosa, CA: Black Sparrow Press, 1980.

FANTE, J. Dreams from Bunker Hill. Santa Rosa, CA: Black Sparrow Press, 1982.

FANTE, J. Espere a primavera, Bandini. São Paulo: Brasiliense, 1990.

FANTE, J. Pergunte ao pó. São Paulo: Brasiliense, 1987.

FANTE, J. Pergunte ao pó. Rio de Janeiro: José Olympio, 2003.

FANTE, J. Rumo a Los Angeles. São Paulo: Brasiliense, 1989.

FANTE, J. Sonhos de Bunker Hill. São Paulo: Brasiliense, 1987.

FANTE, J. The Road to Los Angeles. Santa Rosa, CA: Black Sparrow Press, 1985.

FANTE, J. Wait Until Spring, Bandini. 1938. Santa Rosa, CA: Black Sparrow Press, 1983.

FANTE, J. MENCKEN. H. L. Correspondance 1930-1952. Paris: Christian Bourgois Éditeur, 1991.

KRISTEVA, J. Tocata e fuga para o estrangeiro. In: KRISTEVA, J. Estrangeiros para nós mesmos. Tradução de Maria Carlota C. Gomes. Rio de Janeiro: Rocco, 1994. p. 9-46.

LEJEUNE, P. O pacto autobiográfico: de Rousseau à Internet. Tradução de Jovita Maria Gerheim Noronha, Maria Inês Coimbra Guedes. Belo Horizonte: UFMG, 2008.

LEMINSKI, P. Prefácio. In: FANTE, John. Pergunte ao pó. São Paulo: Brasiliense, 1987. s.p.

LIMA, M. F. "As coisas não estão assim tão mal dentro da minha pele": a autoficção em Tanto faz, de Reinaldo Moraes. Scripta Uniandrade, Curitiba, v. 16, n. 1, p. 183-202, 2018.

LÍSIAS, R. O céu dos suicidas. Rio de Janeiro: Alfaguara, 2012.

LÍSIAS, R. Divórcio. Rio de Janeiro: Alfaguara, 2013.

WATT, I. A ascensão do romance. Tradução de Hildegard Feist. São Paulo: Cia. das Letras, 1990. 